\title{
Commentary: The slow history of progress
}

\author{
Dawn S. Hui, MD
}

Equity of access, treatment, and outcomes has been a hot topic of late in cardiovascular medicine. Yet, it was more than 35 years ago that attention to this topic was first raised at the federal level. In 1985, the Reagan Administration issued the Report of the Secretary's Task Force on Black and Minority Health, ${ }^{1}$ the first comprehensive federal report on the health status of racial and ethnic minorities. Informally named after the Department of Health and Human Services (HHS) Secretary Margaret Heckler, the so-called Heckler Report identified cardiovascular diseases as among the top causes of excess deaths in minorities (Figure 1). The impetus for the study came from Heckler's meeting with a group of esteemed figures who presented the findings of a report from the Association of Minority Health Professions Schools $^{2}$ : Louis Sullivan, MD, the first dean of Morehouse School of Medicine and future HHS Secretary; David Satcher, MD, PhD, then-president of Meharry Medical College, future HHS Secretary and 16th US Surgeon General; Walter Bowie, DVM, Dean of Tuskegee University; and M. Alfred Haynes, MD, MPH, Dean of Charles R. Drew University of Medicine and Science (Figure 2). ${ }^{3,4}$

Pienta and colleagues ${ }^{5}$ examine disparities in mitral repair rate and mitral surgery outcomes utilizing the Michigan statewide database. Although all races were included, the study focused on differences in the Black population, with 3 major findings: compared with White patients, operative mortality was similar but readmission rates were higher in Black patients, unadjusted mitral repair rates were lower in Black patients, and repair rate differences

From the Department of Cardiothoracic Surgery, Joe R. and Teresa Lozano Long School of Medicine, UT Health San Antonio, San Antonio, Tex.

Disclosures: The author reported no conflicts of interest.

The Journal policy requires editors and reviewers to disclose conflicts of interest and to decline handling or reviewing manuscripts for which they may have a conflict of interest. The editors and reviewers of this article have no conflicts of interest.

Received for publication Jan 11, 2022; revisions received Jan 11, 2022; accepted for publication Jan 11, 2022; available ahead of print Jan 14, 2022

Address for reprints: Dawn S. Hui, MD, Department of Cardiothoracic Surgery, Joe R. and Teresa Lozano Long School of Medicine, UT Health San Antonio, 7703 Floyd Curl Dr, Suite 211L, San Antonio, TX 78229 (E-mail: huid@uthscsa.edu). J Thorac Cardiovasc Surg 2023;165:1824-6

0022-5223/\$36.00

Copyright (c) 2022 by The American Association for Thoracic Surgery

https://doi.org/10.1016/j.jtcvs.2022.01.014

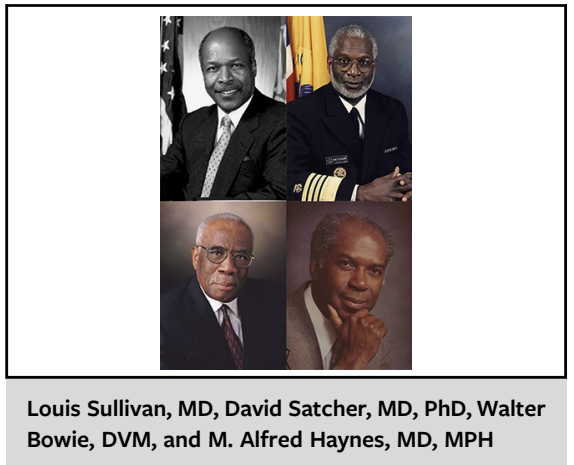

CENTRAL MESSAGE

Mitral surgery mortality is not

higher in Black patients, but

persistent disparities in other

outcomes may be an effect of

social determinants of health,

referral patterns, or treatment

biases.

were no longer present after multivariable adjustment. When it comes to equity of treatment and outcomes in mitral surgery, there are multiple components to consider. Early operative mortality was not worse in Black patients, despite a higher risk profile and counter to the authors' hypothesis, which is a positive and encouraging finding. Yet, other results reveal opportunities for further study or improvement. First, the etiology of mitral disease differed between groups, a finding reflected in other surgical series wherein the proportion of degenerative disease is higher in White patients. ${ }^{6,7}$ An echocardiogram-based study out of London showed similar racial differences. ${ }^{8}$ One must approach any clinically based observational study with caution due to the potential for referral bias along racial lines. Understanding whether true etiologic differences exist, and whether they are due to differences in biology, social determinants, or comorbid conditions will require population-based investigations that are currently lacking. A gap between the demographic characteristics of the study patients and Michigan state $(11.1 \%$ vs $15.0 \%$ Black) is difficult to interpret without this information.

Second, other quality indicators of the care of mitral valve patients were somewhat disappointing. The rate of concomitant maze procedures in patients with atrial fibrillation was higher in White patients. Concomitant maze procedure is not only well established to be safe, but it is 


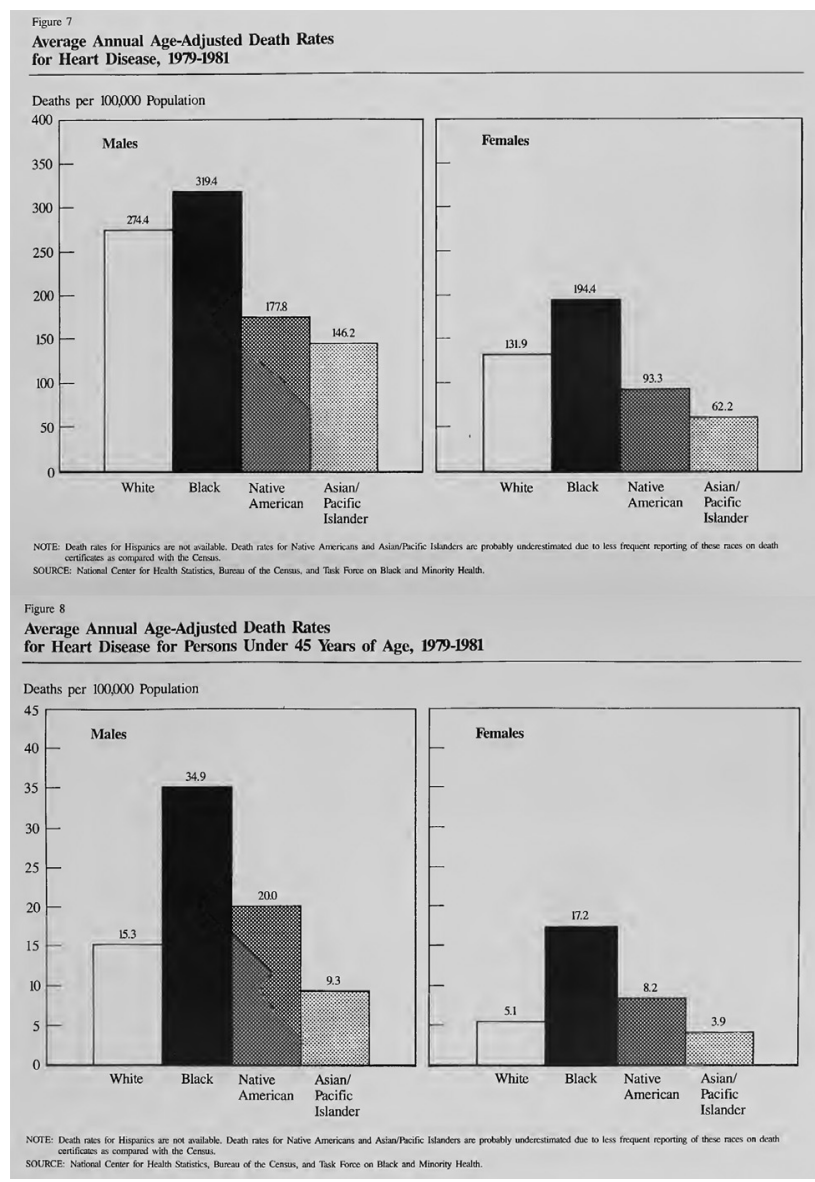

FIGURE 1. Cardiovascular mortality comparison from the Heckler Report. ${ }^{1}$

also a Class I Level of Evidence A recommendation in the Society of Thoracic Surgeons Clinical Practice Guideline. ${ }^{10}$ Most importantly, lower unadjusted repair rates raise the somewhat philosophical question of what statistical adjustment means for mitral repair selection. With the known superior short-, mid-, and long-term benefit of mitral repair over replacement (even in older patients), ${ }^{11}$ valve reparability should be the primary adjustment factor in any analysis. The multivariable adjustment used by Pienta and colleagues $^{5}$ may be somewhat a proxy for operative decision making but cannot possibly reflect the surgeons' assessment on a reparability. It should be noted that the Society of Thoracic Surgeons predictive risk modeling automatically assigns a higher risk score to mitral replacement than mitral repair. Therefore, higher operative risk may reflect comorbid conditions, procedure selection, or both.

Finally, the study by Pienta and colleagues ${ }^{5}$ of the excellent Michigan outcomes should by no means be interpreted to reflect the national experience. A pair of studies from 2008 and 2011 is illustrative. Patients treated at 2 New York City hospitals from 1992 to 2003 had mitral repair rates of $66.4 \%$ in White patients and $51.2 \%$ in Black

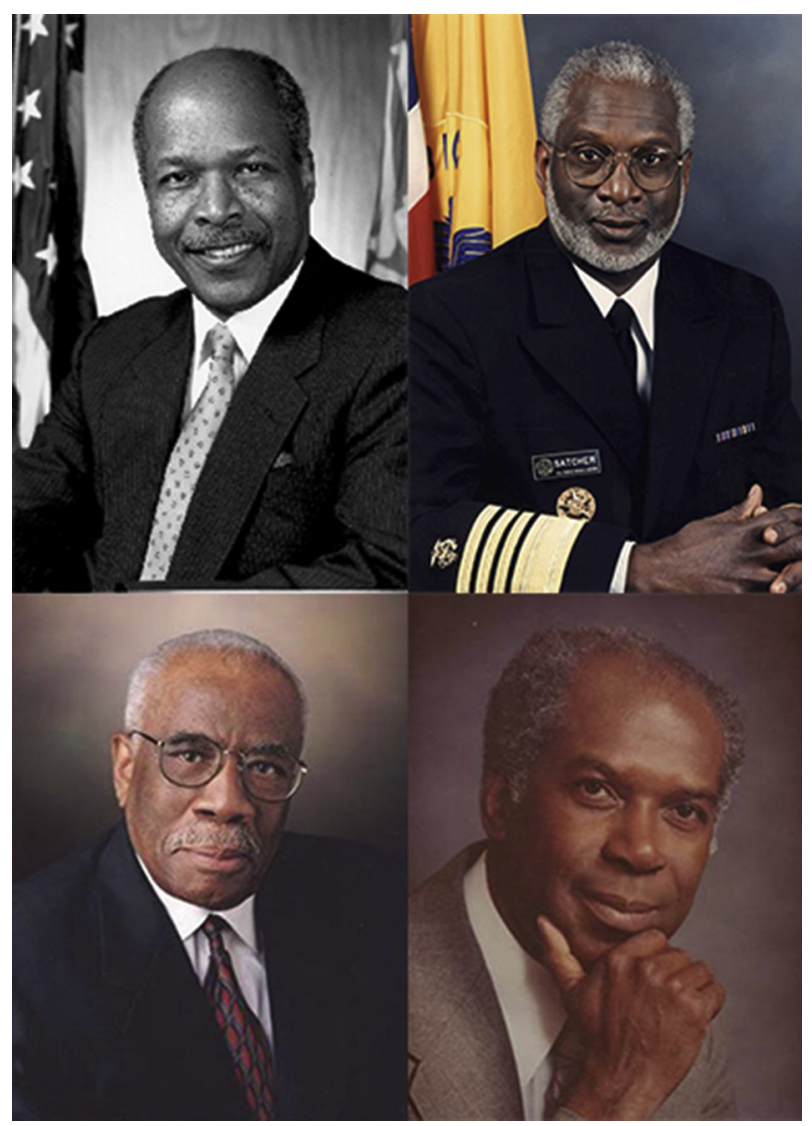

FIGURE 2. Louis Sullivan, MD, David Satcher, MD, PhD, Walter Bowie, DVM, and M. Alfred Haynes, MD, MPH.

patients, ${ }^{6}$ (rates similar to Pienta and colleagues ${ }^{5}$ ), whereas a study of the National Inpatient Sample Database from 2005 to 2007 showed similar racial disparity but much lower repair rates overall $(48.3 \%$ White and $35.6 \%$ Black). ${ }^{7}$

Reflecting on health inequities in the current era, Rosenbaum $^{12}$ wrote that "national reports and specialized studies are undoubtedly invaluable, but... are not substitutes for real-time information grounded in actual practice. Ifas it should be-the goal is not simply to document the existence of health care inequities but to measure it in actual practice and do something about it." Studies such as that by Pienta and colleagues ${ }^{5}$ may help us focus our attention to the actual practices to be examined to effect change but requires acknowledgement of and deeper reflection on our surgical practices.

\section{References}

1. Heckler M. Report of the secretary's task force report on black and minority health volume I: executive summary. Accessed January 17, 2022. https:// minorityhealth.hhs.gov/assets/pdf/checked/1/ANDERSON.pdf

2. Hanft R, Fishman L, Evans W. Blacks and the Health Professions in the 1980s: A National Crisis and a Time for Action. A Paper Prepared for the Association of Minority Health Professions Schools; 1983. 
3. Sullivan LW. The Heckler report: reflecting on its beginnings and 30 years of progress; 2015. Accessed January 17, 2022. https:/www.minorityhealth.hhs. gov/Blog/BlogPost.aspx?BlogID $=82$

4. Garcia N. Remembering Margaret Heckler's commitment to advancing minority health; 2018. Accessed January 17, 2022. https://www.healthaffairs.org/do/10. 1377/forefront.20181115.296624

5. Pienta MJ, Theurer P, He C, Zehr K, Drake D, Murphy E, et al. Racial disparities in mitral valve surgery: a statewide analysis. J Thorac Cardiovasc Surg. 2023; 165:1815-23.

6. DiGiorgi PL, Baumann FG, O'Leary AM, Schwartz CF, Grossi EA, Ribakove GH, et al. Mitral valve disease presentation and surgical outcome in African-American patients compared with white patients. Ann Thorac Surg. 2008:85:89-93.

7. Vassileva CM, Markwell S, Boley T, Hazelrigg S. Impact of race on mitral procedure selection and short-term outcomes of patients undergoing mitral valve surgery. Heart Surg Forum. 2011;14:E221-6.
8. Hayward C, Monteiro R, Ferreira A, Fernandes S, Mouyis K, Patel H, et al. Racial differences in the aetiology of mitral valve disease. Eur Heart J Qual Care Clin Outcomes. 2021;7:e3-4.

9. Vital Statistics Michigan. Population by Race \& Hispanic Ancestry, Michigan 2000-2019. Accessed January 2, 2022. https://vitalstats.michigan.gov/osr/ Population/npPopBYRace.asp

10. Badhwar V, Rankin JS, Damiano RJ Jr, Gillinov AM, Bakaeen FG, Edgerton JR, et al. The Society of Thoracic Surgeons 2017 clinical practice guidelines for the surgical treatment of atrial fibrillation. Ann Thorac Surg. 2017;103:329-41. https://doi.org/10.1016/j.athoracsur.2016.10.076

11. Gaur P, Kaneko T, McGurk S, Rawn JD, Maloney A, Cohn LH. Mitral valve repair versus replacement in the elderly: short-term and long-term outcomes. J Thorac Cardiovasc Surg. 2014;148:1400-6. https://doi.org/10.1016/j.jtcvs.2014.01.032

12. Rosenbaum $S$. Eliminating inequity in health care demands measurement in real time. Accessed January 17, 2022. https://www.milbank.org/quarterly/opinions/ eliminating-inequity-in-health-care-demands-measurement-in-real-time/
See Article page $\mathbf{1 8 1 5}$

\section{Commentary: Race and medicine: Not all differences are disparities}

\author{
Paul Kurlansky, MD
}

Understanding and addressing disparities in health care is a national and professional priority. For nearly 2 decades, Congress has mandated the Agency for Healthcare Research and Quality to generate annual National Healthcare Quality and Disparities Report based on more than 250 measures of quality and covering a broad range of health care services and settings. ${ }^{1}$ A query of PubMed for "health disparities" will yield more than 85,000 results with a logarithmic acceleration over recent years (Figure 1). ${ }^{2}$ Understanding racial differences in medicine is particularly challenging. Race is a social construct inadequate to describe the distribution of genetic variation in our species. ${ }^{3}$ Therefore, distinguishing scientific from social and political determinants of health can be a difficultbut very important—task. Political solutions to scientific

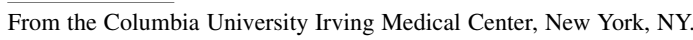

Disclosures: The author reported no conflicts of interest.

The Journal policy requires editors and reviewers to disclose conflicts of interest and to decline handling or reviewing manuscripts for which they may have a conflict of interest. The editors and reviewers of this article have no conflicts of interest.

Received for publication Nov 22, 2021; revisions received Nov 22, 2021; accepted for publication Nov 23, 2021; available ahead of print Nov 26, 2021.

Address for reprints: Paul Kurlansky, MD, Columbia University Irving Medical Center, Neurological Institute 554, 710 West 168th St, New York, NY 10032 (E-mail: Pk2245@cumc.columbia.edu).

J Thorac Cardiovasc Surg 2023;165:1826-7

$0022-5223 / \$ 36.00$

Copyright (c) 2021 by The American Association for Thoracic Surgery

https://doi.org/10.1016/j.jtcvs.2021.11.060
Check for updates

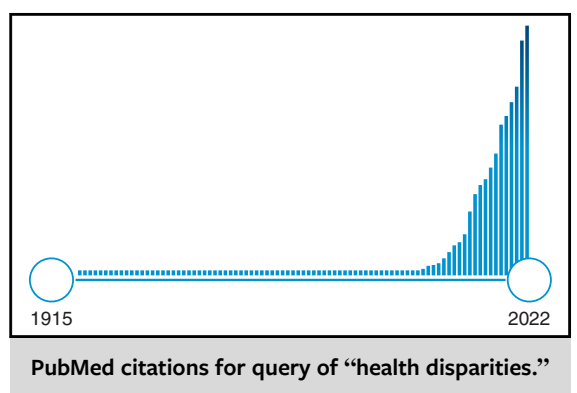

CENTRAL MESSAGE

Careful analysis of racial differ-

ences in presentation and

outcome of surgical procedures

is essential to better understand

the specific role of race in surgi-

cal disease.

problems rarely succeed, but the search for the scientific basis of political problems is a similarly futile undertaking. Although surgical care focuses on a very specialized segment of the broad spectrum of health care, operative decisions and outcomes are inextricably tied to the general environment in which they occur.

It is in this context that the carefully constructed analysis of mitral valve surgery in the state of Michigan reported in this issue of the Journal presents an important contribution to our understanding of racial disparities in surgical care. ${ }^{4}$ Leveraging the robust clinical data from the Society of 